\title{
Modeling the Effects of Wind Redistribution on the Snow Mass Budget of Polar Sea Ice*
}

\author{
Stephen J. DÉRY AND L.-B. TREMBlay \\ Lamont-Doherty Earth Observatory, Columbia University, Palisades, New York
}

(Manuscript received 14 January 2003, in final form 5 June 2003)

\begin{abstract}
A two-dimensional numerical model of blowing snow specifically designed for sea ice environments is presented. This new model is used to quantify the snow mass lost because of blowing snow into leads, blowing snow sublimation, and the effects of snow redistribution in the presence of surface irregularities (e.g., pressure ridges and snowdrifts) and on the conductive heat flux through the ice. Results show that the percentage of blowing snow lost into open waters (i.e., the lead trap efficiency) ranges between $60 \%$ and $100 \%$. The lead trap efficiency increases with fetch over open waters, decreases as the upwind fetch over sea ice expands, and diminishes as wind speeds and friction velocities are enhanced. Its dependence on air temperature and relative humidity, however, is relatively small. Results from the time evolution of a snowdrift show that considerable snow cover heterogeneity arises because of interactions between winds and the surface; however, the corresponding increase in the conductive heat flux through the ice remains small (an increase of approximately $0.13 \%$ for a typical snowdrift distribution over a 1-km fetch). Results show that the snow mass lost into leads $\left(Q_{l}\right)$ depends strongly on the number of leads (for a fixed total open water fraction), suggesting that the lead distribution also needs to be considered in a parameterization of $Q_{l}$ in terms of meteorological conditions and surface characteristics. The results of this study provide some basic information on the small-scale processes influencing blowing snow over sea ice; these can then be used to evaluate the precise role that blowing snow plays in the surface energy and mass balances of large-scale models.
\end{abstract}

\section{Introduction}

At high latitudes, the world's oceans are covered by perennial or seasonal ice cover. Since subfreezing temperatures persist throughout most of the year, precipitation generally falls in the form of snow, blanketing the ice pack with a thin layer of highly reflective and insulating material. With its higher albedo, lower thermal conductivity, and higher attenuation for shortwave radiation (when compared with sea ice), snow reflects a large amount of incoming solar radiation, insulates well the underlying ocean from the air above during the cold season, and limits the amount of energy (and light) reaching the ice and mixed layer. Since the conductive heat flux through the ice is directly related to the snow thickness, a good understanding of snow redistribution over sea ice is crucial.

Snow-covered sea ice typically has a low surface roughness such that lower wind speeds are required to produce blowing snow events when compared with most

* Lamont-Doherty Earth Observatory Contribution Number 6477.

Corresponding author address: Stephen J. Déry, 206D Oceanography, Lamont-Doherty Earth Observatory, Columbia University, Palisades, NY 10964-8000.

E-mail: dery@1deo.columbia.edu land areas. For instance, a climatology of these events shows that blowing snow occurs up to 100 days per year over the Arctic Ocean (Déry and Yau 1999a). Three main features associated with this process can affect significantly the surface mass and energy budgets of snow-covered sea ice (Fig. 1). First, blowing snow sublimation perturbs considerably the surface sensible and latent heat fluxes (Déry et al. 1998). This results in the cooling and moistening of the lower atmosphere while inducing a net loss of mass from the snowpack (Déry and Yau 2002, hereinafter referred to as DY02). Preliminary work by the authors using snow and meteorological data from the Surface Heat Budget of the Arctic Ocean (SHEBA) experiment suggests that approximately $30 \%$ of the annual snowfall over sea ice at the SHEBA ice camp is lost through blowing snow sublimation. Second, the presence of leads may collect significant amounts of snow mass transported by low-level winds. Using a simple empirical relation for snow transport and meteorological data from a drifting buoy, Eicken et al. (1994) estimated a mass loss of $100 \mathrm{~mm} \mathrm{yr}^{-1}$ snow water equivalent (swe) from neighboring snowcovered sea ice into leads of the Weddell Sea. Third, microrelief over sea ice associated with snowdrifts and pressure ridges induce a nonuniform pattern in snow depth over sea ice. In fact, the snow contained in large 
drifts can be several times as deep as snow in nondrift areas, thereby modifying the heat transfer between the ocean and the atmosphere (Iacozza and Barber 1999; Warren et al. 1999; Sturm et al. 2002).

There are abundant observational data suggesting the presence of significant ongoing changes in the polar regions in response to global warming (e.g., Serreze et al. 2000). For instance, Arctic sea ice has diminished in both extent and thickness during the last century (e.g., Cavalieri et al. 1997; Rothrock et al. 1999) and has evolved toward a state more favorable to the development of leads (Rigor et al. 2002). Warren et al. (1999) report a decreasing trend (of $-2 \mathrm{~mm} \mathrm{yr}^{-1}$ in May between 1954 and 1991) in the observed end-of-winter snow depth (at several drifting buoys) over Arctic sea ice. During the same period, storminess and precipitation (both solid and liquid) have increased over the Arctic (Colony et al. 1998; Serreze et al. 2000; Walsh 2000). If these trends in open waters and amount of precipitation persist, as is suggested in some recent studies (e.g., Hunt et al. 1995; Vinnikov et al. 1999; Miller and Russell 2000), then the relative impact of blowing snow in the surface mass balance of Arctic sea ice is likely to accentuate in the future.

To study the process of blowing snow and its complex interactions with the surface and the atmospheric boundary layer $(\mathrm{ABL})$, a myriad of numerical models has recently emerged (e.g., Pomeroy et al. 1997; Liston and Sturm 1998; Déry et al. 1998; Bintanja 2000a,b; Xiao et al. 2000). Most of these models, however, have been designed for land environments and accordingly are not able to account for step changes in surface boundary conditions (e.g., associated with the presence of leads or ridges). One exception is the WINDBLAST model developed by Mann (1998) for application over the Brunt Ice Shelf at Halley, Antarctica. However, this column model of blowing snow also assumes uniform upwind conditions and so does not resolve leads or snowdrifts that may be present along the surface.

A few recent studies have broached the subject of blowing snow over sea ice. For instance, using the reanalysis dataset from the European Centre for MediumRange Weather Forecasts (ERA15: Gibson et al. 1997), Déry and Yau (1999a) compiled a global climatology of blowing snow events for the period 1979-93. This climatology revealed that regions covered by sea ice are subject to frequent episodes of blowing snow. DY02 subsequently established that sublimation during transport (23 $\left.\mathrm{mm} \mathrm{yr}^{-1} \mathrm{swe}\right)$, rather than mass divergence $(0.1$ $\mathrm{mm} \mathrm{yr}^{-1} \mathrm{swe}$ ), is the dominant factor affecting the largescale surface mass balance of snow-covered Arctic sea ice associated with blowing snow events. Their study, however, does not take into account the effect of leads in the sea ice cover because of the relatively coarse horizontal resolution of their sea ice mask $\left(2.5^{\circ}\right.$ lat $\times$ $2.5^{\circ}$ lon). Déry and Yau (2001a) also conducted a highresolution (18-km pixel) mesoscale simulation of an Arctic ground blizzard over the Beaufort Sea in No- vember 1996. Infrared satellite imagery at resolutions of $1 \mathrm{~km}$ collected during this clear-sky event revealed the presence of numerous leads, unresolved in the mesoscale model. During this severe windstorm, blowingsnow transport rates surpassed 30 tons per meter of width over a 2-day period, suggesting that considerable mass could be transferred into leads during such events. Fichefet and Morales Maqueda (1999) conducted a large-scale modeling study of blowing snow and its role in the formation of sea ice in the Southern Ocean. Although they determined that snow redistribution does not enhance the formation of sea ice in their coupled snow-sea ice-mixed layer model, they nonetheless concluded that it contributes substantially to the surface mass balance. In their simulations, an arbitrarily chosen amount of snow $(25 \%-50 \%$ of the grid snowfall) was transferred into open waters without explicitly resolving blowing-snow events, leads, and polynyas.

Although there have been a number of recent efforts at examining the evolution of a snowpack over sea ice (e.g., Hanesiak et al. 1999; Jordan et al. 1999), few studies have considered explicitly the role of blowing snow in the surface mass and heat budgets of snowcovered sea ice. The objective of this study is to quantify the mass transport of blowing snow into open waters on the snow mass budget of polar sea ice and to evaluate the effects of snow redistribution on the conductive heat flux through the ice. To this end, we present a highresolution numerical model specifically designed for the sea ice environment. Several numerical experiments over idealized domains are performed to quantify 1) the loss of snow into open waters or by sublimation of airborne snow particles and 2) the influence of a snowdrift on the snow thickness distribution and on the conductive heat flux through sea ice. The simulations are conducted at high spatial resolutions $(1 \mathrm{~m})$ with horizontal domains of a few kilometers. Preliminary results hinting at the fact that snow mass loss into leads can be parameterized in terms of the total open water fraction and a lead width distribution are also presented. The results of this study provide useful information on the small-scale processes influencing blowing snow over sea ice; these can then be used to develop detailed parameterizations for coarser-resolution models.

The paper is structured as follows. In section 2, the model entitled PIEKTUK-TUVAQ (meaning blowing snow and sea ice in the Inuit language of Inuktitut) is described. The numerical scheme and the model boundary conditions are presented in section 3. Results are presented in section 4 , and the sensitivity of the model to ambient surface and atmospheric conditions is investigated in section 5. A discussion of the results is included in section 6 , and conclusions and potential future applications of the model are summarized in section 7 .

\section{Model description \\ a. Background}

Blowing and drifting snow occur when loose snow at the surface is entrained by winds into two substantive 
modes of transport: saltation and suspension. Saltation is the action by which particles of snow bounce or skip along the surface up to heights of a few centimeters. Through repeated surface collisions, the abrasion of saltating snow particles occurs rapidly such that they approach the density of ice. If turbulent motions in the $\mathrm{ABL}$ are sufficiently strong, some of the particles from the saltation layer may then be entrained into the suspension mode. In this situation, a balance between downward gravitational settling and upward turbulent diffusion leads to the suspension of blowing snow. In severe blizzards, snow particles transported by turbulent eddies can be found up to several hundred meters above the surface (King and Turner 1997).

The model used to simulate these processes is based on the PIEKTUK blowing snow model, developed for the Arctic tundra (Déry and Taylor 1996; Déry et al. 1998). For completeness, a brief history of PIEKTUK is given here. PIEKTUK depicts the evolution of a column of blowing snow in a neutral ABL. It predicts the absolute number density of blowing snow particles for various size bins (typically 64) (Déry et al. 1998). For this reason, the model first became known as the spectral PIEKTUK (or PIEKTUK-S). In addition, PIEKTUK-S includes two prognostic thermodynamic quantities that are affected by blowing-snow sublimation: the air temperature $T_{a}(\mathrm{~K})$ and the water vapor mixing ratio $q_{v}(\mathrm{~kg}$ $\mathrm{kg}^{-1}$ ). This model compared well with blowing snow measurements and several meteorological variables collected during two major field campaigns (Xiao 2001): at Halley, Antarctica, during the second Stable Antarctic Boundary Layer Experiment (STABLE2; Mann et al. 2000) and another field experiment conducted in Wyoming (Schmidt 1982).

To reduce the computational demands of PIEKTUKS, Déry and Yau (1999b) derived a bulk equation for the blowing-snow mixing ratio $q_{b}\left(\mathrm{~kg} \mathrm{~kg}^{-1}\right)$ by integrating the frequency distribution of blowing-snow particles over all radii. To do this, it was assumed that a two-parameter gamma distribution represented the partitioning of the suspended blowing snow based on observations by Budd (1966), Schmidt (1982), and Mann (1998). This new version, which relies on the bulk mixing ratio of blowing snow (referred to as PIEKTUK-B), is approximately 100 times as fast as its spectral counterpart (Déry and Yau 1999b). In an intercomparison of four blowing-snow models (Xiao et al. 2000), it was demonstrated that PIEKTUK-B predicted the blowing snow fluxes in varying ambient conditions with similar accuracy as more detailed models. However, the assumption of constant total particle numbers $N\left(\mathrm{~m}^{-3}\right)$ in time in this model was not consistent with the evolution of $q_{b}$. To relax this constraint on $N$, a new evolution equation was introduced leading to an improved overall simulation of blowing snow particle distributions (Déry and Yau 2001b). Since $N$ and $q_{b}$ represent the zeroth and third moments of a gamma distribution of blowingsnow particles, this version of the model was identified as the double-moment PIEKTUK model (PIEKTUK-D). This model was run only in circumstances in which a "blowing-snow event" is detected from the ambient conditions. These situations are defined as times when the surface is snow covered, $T_{a}<0^{\circ} \mathrm{C}$, and wind speeds surpass a certain threshold (Déry and Yau 1999a). In PIEKTUK-TUVAQ, inhomogeneous surface conditions such as leads and ridges, and the effects of the ABL stability (important over leads) are included. In the following, the governing equations and new features related to the sea ice environment are presented.

\section{b. Basic equations}

PIEKTUK-TUVAQ operates in a time- and fetchdependent mode. In this model, it is assumed that all state variables satisfy an evolution equation of the form

$$
\frac{\partial A}{\partial t}+U \frac{\partial A}{\partial x}=\frac{\partial}{\partial z}\left(K_{A} \frac{\partial A}{\partial z}+v_{t} A\right)+S
$$

where $A(t, x, z)$ stands for one of the four prognostic variables $\left(N, q_{b}, T_{a}, q_{v}\right), t(\mathrm{~s})$ is time, $x$ and $z(\mathrm{~m})$ are the horizontal and vertical coordinates, $U\left(\mathrm{~m} \mathrm{~s}^{-1}\right)$ is the horizontal wind speed, $v_{t}\left(\mathrm{~m} \mathrm{~s}^{-1}\right)$ is the terminal velocity, $K_{A}\left(\mathrm{~m}^{2} \mathrm{~s}^{-1}\right)$ is the eddy diffusion coefficient, and $S$ is a source/sink term that can be related in all instances to the bulk sublimation rate $S_{b}\left(\mathrm{~kg} \mathrm{~kg}^{-1} \mathrm{~s}^{-1}\right)$ of blowing snow. Complete details on the specification of $S$ for each state variable and their units are provided in Déry and Yau (1999b, 2001b). In this equation, the $x$ axis is assumed to be parallel to the low-level flow, and the terminal velocity is only considered for the total number concentration and mixing ratio of blowing snow. The eddy diffusivity coefficients $K_{A}$ can be written as (e.g., Arya 2001)

$$
K_{A}=\phi_{A} u_{*} l,
$$

where $u_{*}\left(\mathrm{~m} \mathrm{~s}^{-1}\right)$ denotes the friction velocity, $\phi_{A}$ is the dimensionless stability function of variable $A$, and

$$
l=\frac{\kappa\left(z+z_{0}\right)}{1+\kappa\left(z+z_{0}\right) / l_{\max }}
$$

is the mixing length (m) (Stull 1988). This quantity is defined in terms of the von Kármán constant $(\kappa=0.4)$, the roughness length for momentum $z_{0}(\mathrm{~m})$, and a maximum value of the mixing length $\left(l_{\max }=40 \mathrm{~m}\right)$ (Taylor 1969). In this model, the friction velocity over sea ice depends on the $10-\mathrm{m}$ wind speed $U_{10}\left(\mathrm{~m} \mathrm{~s}^{-1}\right)$ and is defined as

$$
u_{*}=0.02264 U_{10}^{1.295}
$$

following observations by Pomeroy and Gray (1990). Over open waters, we obtain $u_{*}$ by solving a quadratic equation that depends on the vertical velocity gradient and on $z_{0}$ (see section 2c).

These equations are solved from the top of the saltation layer $(z=0.1 \mathrm{~m})$ to the top of the $\operatorname{ABL}(z=1$ 
$\mathrm{km}$ ). In this manner, we avoid resolving the complex processes taking place in the saltation layer (Anderson and Haff 1991; Doorschot and Lehning 2002). In this framework, it is assumed that the saltation layer responds instantaneously to changes in surface conditions. There are three important diagnostics produced by the model. The first is the vertically integrated blowing snow sublimation rate $Q_{s}\left(\mathrm{~m} \mathrm{~s}^{-1}\right)$ defined as

$$
Q_{s}=-\int_{z=0.1 \mathrm{~m}}^{z=1000 \mathrm{~m}} S_{b} d z
$$

A negative sign is introduced in Eq. (5), since $S_{b}$ is a negative quantity, and, by convention, $Q_{s}$ is reported as a positive quantity. A typical blowing-snow sublimation rate in an Arctic ground blizzard is $1 \mathrm{~mm} \mathrm{day}^{-1}$ swe, equivalent to a surface latent heat flux of $33 \mathrm{~W} \mathrm{~m}^{-2}$ over that period (e.g., Déry and Yau 2001a).

The second is the transport rate of blowing snow $Q_{t}$ $\left(\mathrm{kg} \mathrm{m}^{-1} \mathrm{~s}^{-1}\right)$ given by

$$
Q_{t}=Q_{\text {salt }}+Q_{\text {susp }}=Q_{\text {salt }}+\rho_{a} \int_{z=0.1 \mathrm{~m}}^{z=1000 \mathrm{~m}} q_{b} U d z
$$

where $\rho_{a}\left(\mathrm{~kg} \mathrm{~m}^{-3}\right)$ is the atmospheric density, and $Q_{\text {salt }}$ [specified as in Pomeroy and Gray (1990)] and $Q_{\text {susp }}$ are the saltation and suspension transport rates $\left(\mathrm{kg} \mathrm{m}^{-1} \mathrm{~s}^{-1}\right)$. While $Q_{s}$ leads to the direct loss of snow from the surface, it is the horizontal divergence of $Q_{t}$ that determines whether snow redistribution constitutes a source or a sink in the local surface mass balance. Values of $Q_{\text {susp }}$ exceed $Q_{\text {salt }}$ at all wind speeds except those near the threshold for transport initiation $\left(U_{10} \approx 7-9 \mathrm{~m} \mathrm{~s}^{-1}\right)(\mathrm{Li}$ and Pomeroy 1997). Typical total transport rates of blowing snow attain values of $0.1 \mathrm{~kg} \mathrm{~m}^{-1} \mathrm{~s}^{-1}$ in a moderate wind event $\left(U_{10}=10 \mathrm{~m} \mathrm{~s}^{-1}\right)$ and $0.8 \mathrm{~kg} \mathrm{~m}^{-1} \mathrm{~s}^{-1}$ in strong wind conditions $\left(U_{10}=20 \mathrm{~m} \mathrm{~s}^{-1}\right.$ ) (Déry and Yau 2001b).

The third diagnostic produced by PIEKTUK-TUVAQ is the amount of blowing snow eroded over sea ice and transported into leads $Q_{l}\left(\mathrm{~m} \mathrm{~s}^{-1}\right)$. This quantity, expressed here as a rate referenced to the sea ice area, is written as

$$
Q_{l}=-\frac{\left(Q_{t}^{\text {out }}-Q_{t}^{\text {in }}\right)}{\rho_{w} x_{f}}=\frac{Q_{t}^{\text {in }} T_{\mathrm{eff}}}{\rho_{w} x_{f}}
$$

where $Q_{t}^{\text {in }}$ and $Q_{t}^{\text {out }}$ are the transport rates of blowing snow over the open waters at the beginning and at the end of the lead, $\rho_{w}\left(\mathrm{~kg} \mathrm{~m}^{-3}\right)$ is the density of water, and $x_{f}(\mathrm{~m})$ is the upwind fetch over sea ice along the wind direction. In Eq. (7), $T_{\text {eff }}=1-Q_{t}^{\text {out }} / Q_{t}^{\text {in }}$ represents the "trap efficiency" of the open waters to capture airborne snow. Note that this definition of $T_{\text {eff }}$ excludes the amount of suspended snow that sublimates in the ABL. The treatment of leads in PIEKTUK-TUVAQ is discussed in the following section.

\section{c. New features}

\section{1) INHOMOGENEOUS SURFACES}

Surface heterogeneities in the snow thickness from a few centimeters to a few meters are often observed over ice-covered oceans (Iacozza and Barber 1999; Warren et al. 1999; Massom et al. 2001). Changes in surface conditions may occur with phenomena related to snow transport, such as snow dunes, barchans, and sastrugi, or to sea ice transport, such as pressure ridges and hummocks in regions of convergence or leads and polynyas in regions of divergence (Warren et al. 1999; Sturm et al. 2002). These features must be considered for a realistic representation of the blowing-snow process over snow-covered sea ice at horizontal scales of a few meters.

Following the high-resolution wind measurements in the vicinity of sand dunes by Walker and Nickling (2002), we assume that there is a separation of the lowlevel flow from the surface beyond an obstacle of local height $d h$ (provided the slope is steeper than $9^{\circ}$; Pomeroy et al. 1997). In the region of separation, the snow surface no longer becomes a source of blowing snow particles to the air above. In those instances, we set the lower boundary conditions for $q_{b}$ and $N$ to zero despite the presence of snow at the surface. Since the lower model boundary is above the saltation layer, $Q_{\text {salt }}$ also becomes zero in these areas. This change in the lower boundary conditions results in a net downward flux of blowing snow toward the surface. A total horizontal distance of 5 times that of the obstruction height is taken as the deposition zone in all cases (Walker and Nickling 2002). Figure 1 shows the locations (annotated by D) at which these special lower model boundary conditions are applied.

In situations in which the snow cover is completely depleted (for instance, in a patchy network of snow), the local surface boundary conditions for $q_{b}$ and $N$ are also assigned null values. However, blowing snow may persist at bare locations because of the replenishment of snow from an upwind source. In such a case, mass conservation requires that the snow exiting one grid point does not exceed the upwind amount arriving at the same location. Similar boundary conditions are used for suspended blowing snow particles over leads and polynyas (Fig. 1). In this situation we also set the lower boundary condition for $T_{a}$ to the freezing-point temperature of ocean water $T_{f}(\mathrm{~K})$.

A change in the surface type also affects the surface roughness length $z_{0}(\mathrm{~m})$. Observations of saltating snow during high-wind events in the Canadian prairies show a dependence between $z_{0}$ and $u_{*}$ of the form (Pomeroy and Gray 1990)

$$
z_{0}=\alpha_{c} u_{*}^{2} / g
$$

where $g\left(\mathrm{~m} \mathrm{~s}^{-2}\right)$ is the gravitational acceleration and $\alpha_{c}$ is a constant (set to 0.06). Charnock (1958) found a similar relation over open waters, but with $\alpha_{c}=0.012$. 


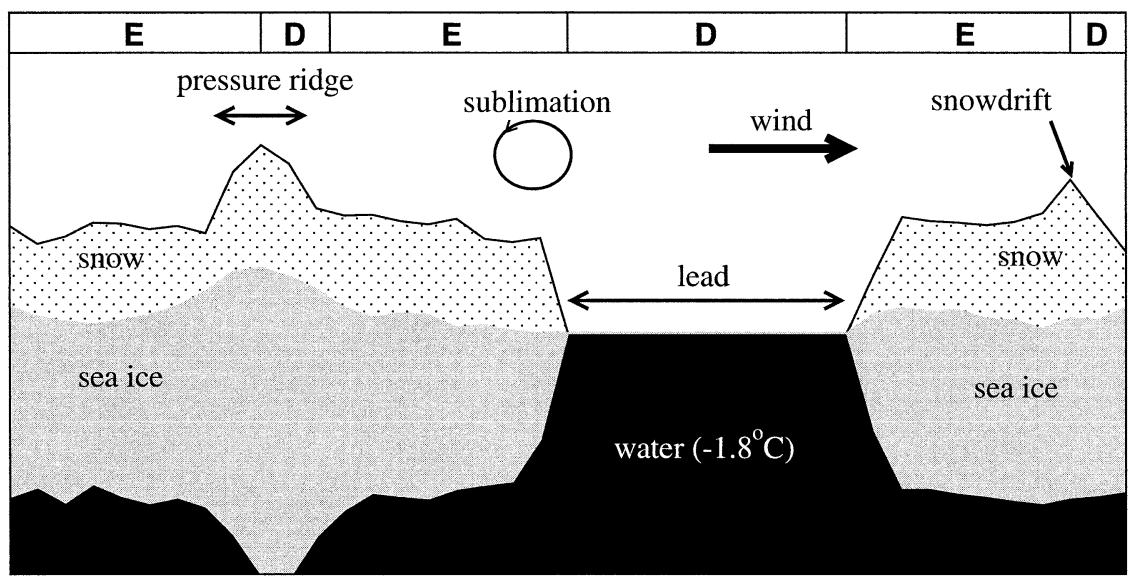

FIG. 1. A schematic representation (not to scale) of typical wintertime features over snowcovered sea ice. Blowing snow carried by strong winds (here from left to right) is transported from erosion areas (E) and accumulates in deposition zones (D).

Equation (8) implies that as wind speed increases, the surface roughness, the friction velocity, and hence the turbulent exchange in the ABL are all enhanced. In cases where the low-level winds separate from the surface (i.e., beyond an obstruction), $z_{0}$ is assigned a typical value for snow of $1 \mathrm{~mm}$ (Oke 1987).

Some authors have questioned the universality of Eq. (8). For instance, Andreas and Claffey (1995) and Andreas (1995) do not find a good correspondence between the measured values of $z_{0}$ and $u_{*}^{2}$ over the sea ice of the Weddell Sea. However, preliminary findings by Jordan et al. (2003) from the SHEBA ice camp support the form of Eq. (8) when $U_{10}>10 \mathrm{~m} \mathrm{~s}^{-1}$ (with $\alpha_{c}=0.03$ ). Consequently, the sensitivity of model results to a range of $u_{*}$ values, corresponding to changes in the drag coefficient $\mathrm{C}_{D}=\left(u_{*} / U\right)^{2}$ will also be tested (see section 5).

\section{2) AtMosPheric STABILITY}

When cold air $\left(\ll-1.8^{\circ} \mathrm{C}\right)$ flows over open waters, large surface latent and sensible heat fluxes develop (Pinto et al. 1995). In such situations, the lower atmosphere destabilizes leading to enhanced turbulent motions within the ABL. This results in strong vertical gradients in the profiles of the thermodynamic and dynamic quantities, particularly near the surface. On the other hand, the suspension of blowing snow imposes a stable stratification upon this two-phase flow due to large vertical density gradients in the suspended snow. This effect, however, only becomes important for highwind conditions (Déry and Taylor 1996; Bintanja 2001).

We express the stability functions in terms of the thermal and particle gradient Richardson numbers $\left(\mathrm{Ri}_{t}\right.$ and $\mathrm{Ri}_{p}$, respectively) defined as (Bintanja 2001)

$$
\begin{aligned}
\mathrm{Ri}_{t}= & \frac{\frac{g}{\theta}\left(\frac{\partial \theta}{\partial z}\right)}{\left(\frac{\partial U}{\partial z}\right)^{2}} \text { and } \\
\mathrm{Ri}_{p}= & -\frac{\partial \frac{\partial q_{b}}{\partial z}}{\left(\frac{\partial U}{\partial z}\right)^{2}},
\end{aligned}
$$

where $\theta(\mathrm{K})$ represents the potential temperature at height $z(\mathrm{~m})$ above the surface. This quantity can be written as

$$
\theta(z)=T_{a}\left[\frac{P(z)}{P_{s}}\right]^{k}
$$

where $k(=0.286)$ denotes the Poisson constant, $P(z)$ $(\mathrm{Pa})$ is the atmospheric pressure at height $z$, and $P_{s}$ is the surface atmospheric pressure (taken here as $1.0 \times$ $\left.10^{5} \mathrm{~Pa}\right)$.

Following Bintanja (2001), we consider the effects of thermal and particle stratification to be additive; that is, $\mathrm{Ri}=\mathrm{Ri}_{t}+\mathrm{Ri}_{p}$. The stability functions for air temperature $\left(\phi_{a}\right)$, water vapor $\left(\phi_{v}\right)$, and momentum $\left(\phi_{m}\right)$ can then be expressed in terms of the total Richardson number (Ri) as proposed by Arya (2001):

$$
\phi_{a}=\phi_{v}= \begin{cases}(1-15 \mathrm{Ri})^{0.50} & \mathrm{Ri}<0 \\ 1-5 \mathrm{Ri} & 0<\mathrm{Ri} \leq 0.2 \\ 1 & \mathrm{Ri}=0\end{cases}
$$

and

$$
\phi_{m}= \begin{cases}(1-15 \mathrm{Ri})^{0.25} & \mathrm{Ri}<0 \\ 1-5 \mathrm{Ri} & 0<\mathrm{Ri} \leq 0.2 \\ 1 & \mathrm{Ri}=0 .\end{cases}
$$


Given the lack of information on the effects of stability on the suspension of blowing snow, we set the values of $\phi_{b}$ and $\phi_{N}$ to those established for momentum (Bintanja 2000a, 2001).

The vertical wind speed profile can be expressed in terms of the vertically integrated $\phi_{m}\left(\psi_{m}\right)$ as (Arya 2001)

$$
U=\frac{u_{*}}{\kappa}\left\{\ln \left[\frac{\left(z+z_{0}\right)}{z_{0}}\right]-\psi_{m}\right\},
$$

where

$$
\psi_{m}= \begin{cases}\ln \left[\left(\frac{1+y^{2}}{2}\right)\left(\frac{1+y}{2}\right)^{2}\right] & -2 \tan ^{-1} y+\frac{\pi}{2} \\ & \mathrm{Ri}<0 \\ -\frac{5 \mathrm{Ri}}{(1-5 \mathrm{Ri})} & 0<\mathrm{Ri} \leq 0.2 \\ 0 & \mathrm{Ri}=0\end{cases}
$$

and

$$
y=(1-15 \mathrm{Ri})^{0.25} .
$$

The inclusion of $\psi_{m}$ in Eq. (14) acts to reduce low-level wind speeds as the ABL becomes increasingly unstable.

\section{Numerical scheme and boundary conditions}

From a set of initial conditions, PIEKTUK-TUVAQ is integrated forward in time using a time step $(\Delta t)$ of $1 \mathrm{~s}$. The horizontal resolution in all simulations is $1 \mathrm{~m}$. In the vertical, a coordinate transformation from $z$ to $\zeta$ $=\ln \left[\left(z+z_{0}\right) / z_{0}\right]$ is conducted to resolve the steep gradients of $q_{b}$ and $N$ near the surface, resulting in a vertical resolution that varies from $0.055 \mathrm{~m}$ near the surface to $326 \mathrm{~m}$ at $z=1 \mathrm{~km}$. The vertical diffusion term is treated implicitly and is discretized using a centered difference scheme; the advection term, on the other hand, is treated explicitly and is discretized using an upstream scheme.

The model upper boundary $\left(z_{\mathrm{ub}}\right)$ is fixed at $1 \mathrm{~km}$ above the local snow surface. At $z_{\mathrm{ub}}$, Neumann boundary conditions are prescribed for all four state variables. At the lower model boundary $\left(z_{\mathrm{lb}}=0.1 \mathrm{~m}\right), q_{b}$ and $N$ are extrapolated from their respective values at the top of the saltation layer using steady-state, analytical profiles of these quantities (see Déry et al. 1998). In deposition areas, both $q_{b}\left(z_{\mathrm{lb}}\right)$ and $N\left(z_{\mathrm{lb}}\right)$ become zero. The lower boundary condition for air temperature is set constant to its initial value at $z_{\mathrm{lb}}$. Over the open waters, $T_{a}\left(z_{\mathrm{lb}}\right)$ is fixed at $-1.8^{\circ} \mathrm{C}$. For moisture, we set $q_{v}\left(z_{\mathrm{lb}}\right)$ to the ice saturation point for both open waters and sea ice. At $x=0$, we take $q_{b}=N=0$ and the thermodynamic quantities to be equal to their initial values (described in the next paragraph).

The initial conditions for $N, q_{b}$, and $T_{a}$ are set to 0 , 0 , and $-20^{\circ} \mathrm{C}$, respectively. The initial profile for $q_{v}$ is taken to be at saturation with respect to ice, a condition often observed over sea ice (Andreas et al. 2002). A

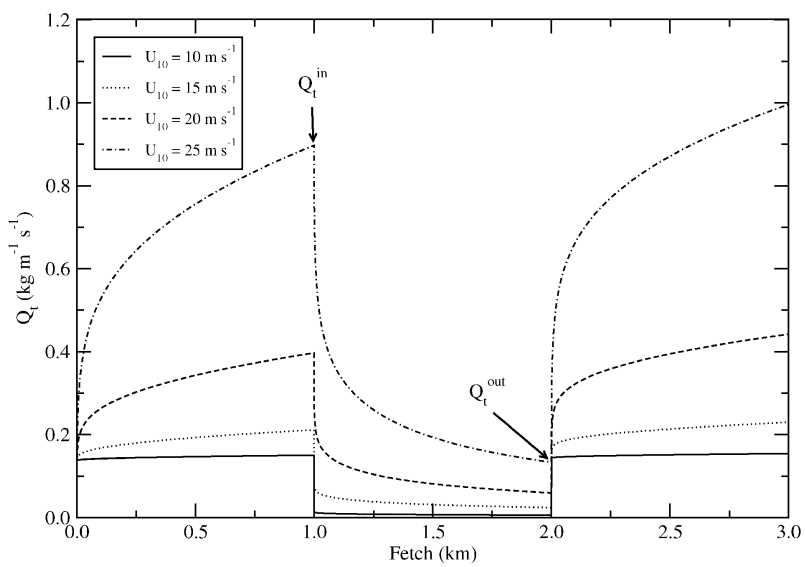

FIG. 2. The spatial evolution of the transport rate of blowing snow $\left(Q_{t}\right)$ for four values of the $10-\mathrm{m}$ wind speed. At $x=1 \mathrm{~km}$, the column of blowing snow traverses open waters over a distance of $1 \mathrm{~km}$ in length before resuming its course over snow-covered sea ice.

nominal $10-\mathrm{m}$ wind speed of $15 \mathrm{~m} \mathrm{~s}^{-1}$ is prescribed to determine the vertical profile of $U$. The initial condition for the snowpack is a depth of $0.2 \mathrm{~m}$, a typical wintertime value over the Arctic (Warren et al. 1999). These conditions define the model's reference state. Except for the case of blowing snow over a snowdrift where surface conditions evolve in time to modify the ambient wind profile and blowing-snow fluxes, steady-state results (i.e., $\partial A / \partial t=0$ ) are presented for all integrations.

In the results section, the passage of a column of blowing snow over a lead and over a snowdrift is investigated. In nature, however, many combinations of these two features may arise along a single trajectory. The intent here is to provide some detailed information on the individual effects of leads and snowdrifts on a column of blowing snow in simple idealized conditions.

\section{Results \\ a. Blowing snow over open waters}

In the first experiment, blowing snow over a lead is investigated. For this test, a 1-km-wide lead perpendicular to the direction of the flow is located at $x=1 \mathrm{~km}$. Results are presented for $10-\mathrm{m}$ wind speeds varying from 10 to $25 \mathrm{~m} \mathrm{~s}^{-1}$. Figure 2 illustrates the abrupt decrease in $Q_{t}$ where blowing snow encounters the open waters and the local source of blowing-snow particles is shut off. The effect is particularly evident at low wind speeds when the upward turbulent transport is smaller and the suspended snow remains closer to the surface. As the column of blowing snow once again flows over sea ice, $Q_{t}$ immediately jumps up to values near those achieved prior to the open waters.

The mass lost $\left(Q_{l}\right)$ over the fetch $x_{f}=1 \mathrm{~km}$ for the four cases presented in Fig. 2 is listed in Table 1. The change in swe increases with wind speed, reaching a mean value of $66 \mathrm{~mm} \mathrm{day}^{-1}$ swe for $U_{10}=25 \mathrm{~m} \mathrm{~s}^{-1}$. 
TABLE 1 . Value of the mass lost into leads $\left(Q_{l}\right)$, trap efficiency $\left(T_{\text {eff }}\right)$ of leads to capture blowing snow, and heat flux $\left(Q_{\text {ocn }}\right)$ associated with the melt of blowing snow in open waters for a range of $10-\mathrm{m}$ wind speeds $\left(U_{10}\right)$. The distance traveled over snow-covered sea ice and over open waters is $1 \mathrm{~km}$. For this case, units of $\mathrm{mm} \mathrm{day}^{-1}$ swe are equivalent to $\mathrm{Mg} \mathrm{m}^{-1} \mathrm{day}^{-1}$.

\begin{tabular}{cccc}
\hline \hline$U_{10}\left(\mathrm{~m} \mathrm{~s}^{-1}\right)$ & $Q_{l}\left(\mathrm{~mm} \mathrm{day}^{-1} \mathrm{swe}\right)$ & $T_{\text {eff }}(\%)$ & $Q_{\text {ocn }}\left(\mathrm{W} \mathrm{m}^{-2}\right)$ \\
\hline 10 & 12.5 & 96.2 & 49.6 \\
15 & 16.2 & 88.5 & 64.1 \\
20 & 29.1 & 84.9 & 115.4 \\
25 & 66.0 & 85.1 & 261.6 \\
\hline
\end{tabular}

In conditions in which the ambient air was not saturated with respect to ice, further depletion of the snowpack would be anticipated because of sublimation. The "trap efficiency" $T_{\text {eff }}$ of the leads to collect blowing snow as well as the heat required to melt this snow ( $Q_{\text {ocn }}$, provided by the ocean surface water) is also shown in Table 1. As wind speed increases, the trap efficiency of the lead diminishes; however, $T_{\text {eff }}$ remains nearly constant at $85 \%$ for $U_{10} \geq 20 \mathrm{~m} \mathrm{~s}^{-1}$. Although $T_{\text {eff }}$ decreases, stronger winds transport more snow in the air column $\left(Q_{t}\right)$ and the total snow mass lost into leads $Q_{l}$ increases. The flux required to bring the snow from $T_{a}$ to $T_{f}$ and to melt it is also listed in Table 1 . The heat required to melt the blowing snow particles increases from $50 \mathrm{~W}$ $\mathrm{m}^{-2}$ at low wind speeds to over $260 \mathrm{~W} \mathrm{~m} \mathrm{~m}^{-2}$ at high wind speeds. These results suggest that blowing snow mass lost into leads exerts a considerable cooling effect on near-surface waters.

The rapid decline in values of $Q_{t}$ over open waters (or their high trap efficiencies) is better understood from $q_{b}$ and $N$ profiles at various downstream locations (Fig. $3)$. As the column of blowing snow reaches $1 \mathrm{~km}, q_{b}$ and $N$ decrease rapidly with height, with maximum values of each quantity attained at $z_{\mathrm{lb}}$. Over the open waters, however, blowing-snow particles begin to fall out of the $\mathrm{ABL}$ in response to the change in the lower boundary conditions. In this situation, the balance between the diffusion process and gravitational settling tends to homogenize the vertical distribution of blowing snow particles near the surface. This is evident by the nearly constant profiles of $q_{b}$ and $N$ from $z=0.2$ to $10 \mathrm{~m}$. However, the overall tendency is for a reduction in the total mass and particle numbers because of the lack of a local source of blowing-snow material. As the lower boundary conditions are reinstated to nonzero values at $x=2 \mathrm{~km}$, the snowpack quickly replenishes the lower levels of the ABL with blowing-snow particles. As a consequence, profiles of $q_{b}$ and $N$ are able to recover only $250 \mathrm{~m}$ downwind from the open waters to vertical distributions nearly equal to those at $x=1 \mathrm{~km}$.
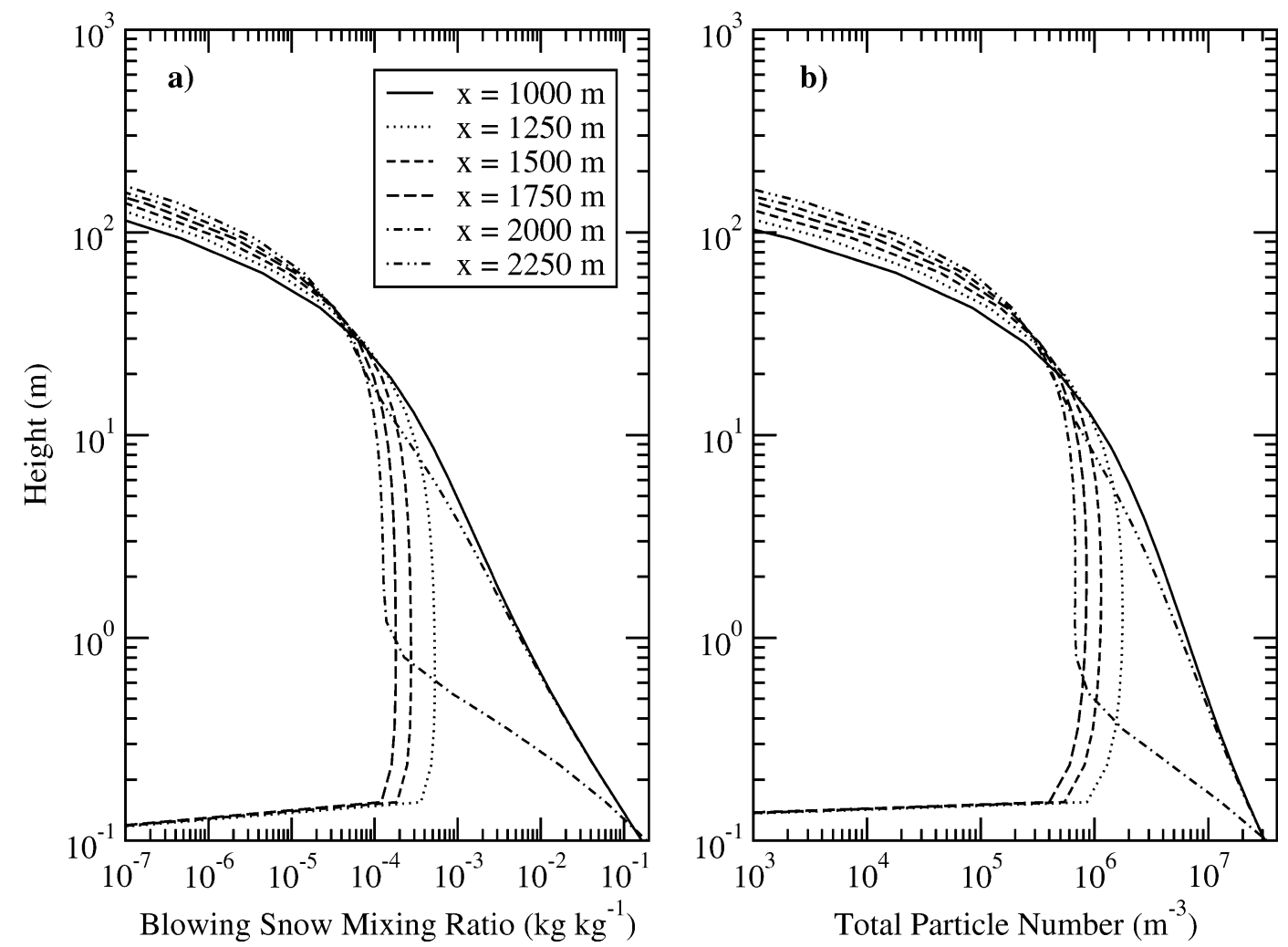

FIG. 3. The vertical profiles of (a) blowing snow mixing ratio $\left(q_{b}\right)$ and (b) total particle numbers $(N)$ at several $x$ locations along the trajectory of the column of blowing snow for $U_{10}=25 \mathrm{~m} \mathrm{~s}^{-1}$. Note the logarithmic scales on each of the plot axes. 


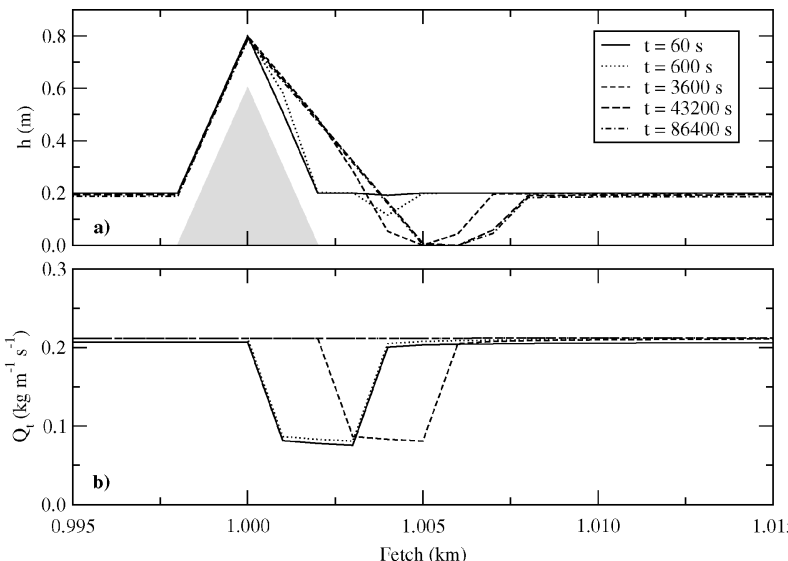

FIG. 4. (a) The spatial and temporal evolution of snow depth (h) in the vicinity of a snowdrift during a blowing-snow event forced by 10 -m wind speeds of $15 \mathrm{~m} \mathrm{~s}^{-1}$. At $t=0$, the snowdrift has a maximum height of $0.8 \mathrm{~m}$ and is centered at $x=1 \mathrm{~km}$. The shaded gray region indicates sea ice. (b) The corresponding instantaneous transport rates of blowing snow $\left(Q_{t}\right)$ that lead to the snowdrift's evolution in (a).

\section{b. Blowing snow over a snowdrift}

In this experiment, the low-level flow encounters a snowdrift at $x=1 \mathrm{~km}$. The snowdrift is represented as a triangular feature having a maximum height of $0.8 \mathrm{~m}$ above the surface covering a horizontal span of $4 \mathrm{~m}$. These are typical dimensions of snowdrifts observed during SHEBA when these features are associated with pressure ridges in the sea ice field (Sturm et al. 2002). In this case, only the top $0.2 \mathrm{~m}$ of the snowdrift is composed initially of snow while the remainder is made up of sea ice. The inclination behind this snowdrift $\left(17^{\circ}\right)$ is $>9^{\circ}$, resulting in the accumulation of snow immediately behind the snow mound (Fig. 4a). As time evolves, the snowdrift expands horizontally as the lee slope becomes less pronounced. Concurrently, significant mass is eroded farther downwind from the snowdrift where the low-level flow reattaches the surface. Observe how points $3-5 \mathrm{~m}$ past the snowdrift are initially $(t \leq 1 \mathrm{~h})$ in a mass erosion zone but later evolve into an accumulation area. After one day, the effects of the barrier are clearly visible even $8 \mathrm{~m}$ downwind from $x=1 \mathrm{~km}$, that is, three times the distance of its original shadow.

Figure $4 \mathrm{~b}$ presents the corresponding transport rates of blowing snow in the vicinity of the snowdrift at several times during the integration. This shows that $Q_{t}$ decreases by up to $60 \%$ as the column of blowing snow intercepts the physical barrier. After $12 \mathrm{~h}$, the lee slopes are reduced (local slope $<9^{\circ}$ ) such that $Q_{t}$ is no longer affected by the presence of the snowdrift and a steady state is nearly achieved. Although the snow depth approaches zero at locations past the shadow of this barrier (i.e., $1.005 \mathrm{~km} \leq x \leq 1.007 \mathrm{~km}$ at $t=1$ day), continuous blowing snow occurring upwind ensures the replenishment of sufficient mass at the surface such that $q_{b}\left(z_{\mathrm{lb}}\right)$ and $N\left(z_{\mathrm{lb}}\right)$ never actually become zero. Even though the
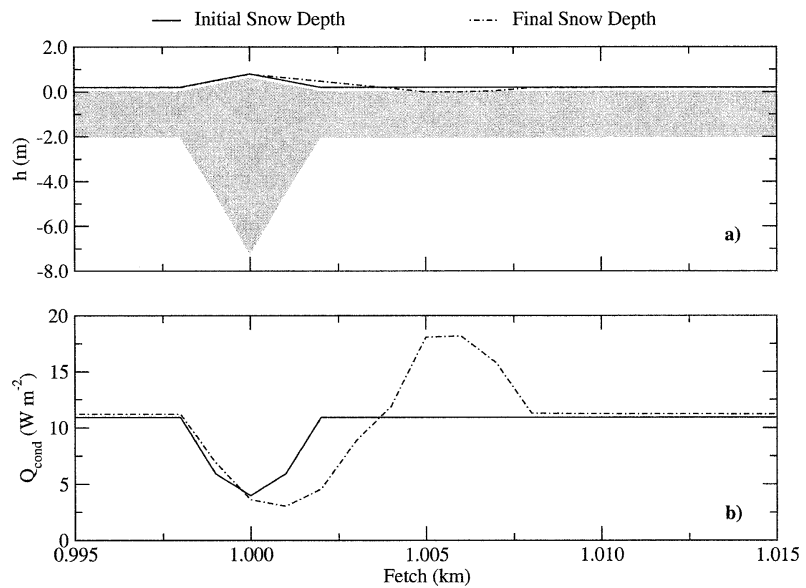

FIG. 5. (a) The spatial distribution of snow depth and ice thickness $(h)$ in the vicinity of a snowdrift before (initial snow depth) and after (final snow depth) a blowing-snow event forced by $10-\mathrm{m}$ wind speeds of $15 \mathrm{~m} \mathrm{~s}^{-1}$. The shaded gray region indicates sea ice. (b) The conductive heat flux through the ice $\left(Q_{\text {cond }}\right)$ for the initial and final snow depth cases. By convention, we indicate a positive heat flux from the ocean toward the atmosphere.

snowdrift has a large impact on $Q_{t}$ in its vicinity, the total snow mass displaced over the 3 - $\mathrm{km}$ domain is reduced by $<0.1 \%$ because of its presence.

To gauge the effects of snow redistribution by wind on the conductive heat flux through the ice, a zero-layer steady-state thermodynamic sea ice model [similar to that of Semtner (1976)] is run using the snow depth at $t=0$ and $t=1$ day over a fetch of $20 \mathrm{~m}$ from Fig. $4 \mathrm{a}$ in the snowdrift experiment. In both cases the ice thickness is fixed at $2 \mathrm{~m}$ except under the ridge where the ice keel is 10 times as deep as its crest. The snow surface temperature is set equal to the air temperature $\left(-20^{\circ} \mathrm{C}\right)$ and the ocean temperature is fixed at $-1.8^{\circ} \mathrm{C}$. Figure 5 shows the two snow depth distributions and the ice thickness in the vicinity of the snowdrift used in the simulations along with their respective conductive heat fluxes through the ice $Q_{\text {cond }}\left(\mathrm{W} \mathrm{m}^{-2}\right)$. For the initial snow thickness distribution, $Q_{\text {cond }}=10.1 \mathrm{~W} \mathrm{~m}^{-2}$ whereas for the final snow thickness distribution, $Q_{\text {cond }}=10.8$ $\mathrm{W} \mathrm{m}{ }^{-2}$ (i.e., a difference of $0.7 \mathrm{~W} \mathrm{~m}^{-2}$ over a distance of $20 \mathrm{~m}$ ). Since a $60-\mathrm{cm}$ ridge occurs approximately every kilometer (Wadhams 2000), $0.7 \mathrm{~W} \mathrm{~m}^{-2}$ over a 20 -m fetch scales to $1.3 \times 10^{-3} \mathrm{~W} \mathrm{~m}^{-2}$ on average over larger domains, or a $0.13 \%$ difference. This difference in the conductive heat flux through the ice is small when compared with other uncertainties in model physics or forcing fields (e.g., amount of precipitation) and can be ignored safely for typical pressure ridge distributions in the polar ocean.

\section{c. Effects of atmospheric stability and sublimation}

In this section, we investigate the effects of atmospheric stability on the flow of a column of blowing snow over a lead (Fig. 6). Prior to the lead, the transport 

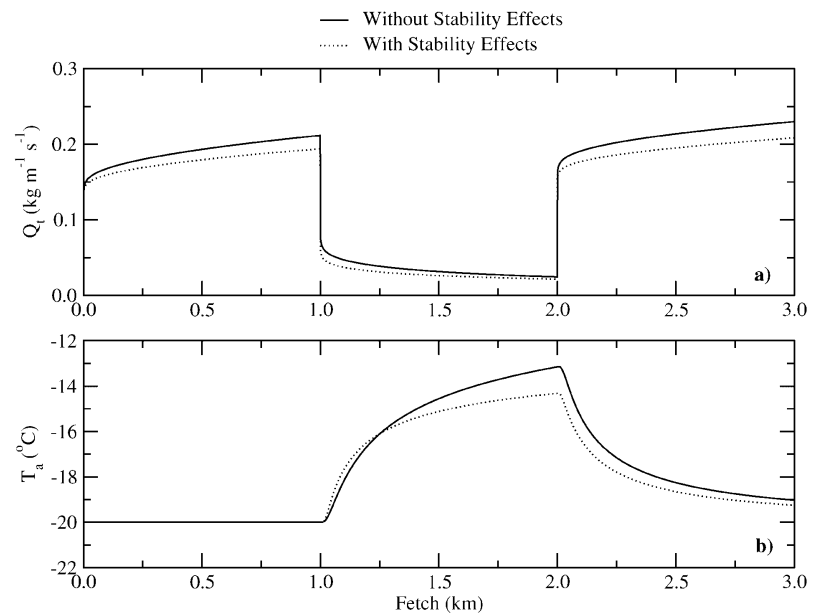

FIG. 6. The spatial evolution of (a) the transport rate of blowing snow $\left(Q_{t}\right)$ and (b) the 2.5-m air temperature $\left(T_{a}\right)$ as a column of blowing snow encounters open waters at $x=1 \mathrm{~km}$ for a distance of $1 \mathrm{~km}$.

rate of blowing snow is reduced slightly owing to particle stratification and as thermal stratification approaches zero. Over the open waters, a thermal destabilization of the ABL occurs because of the change in surface conditions. The instability caused by the strong vertical temperature gradients counters any stratification owing to blowing snow such that $\mathrm{Ri} \approx 0$ and $Q_{t}$ from the two simulations are nearly identical at $x=2 \mathrm{~km}$. For the air temperature, there is little difference between the two simulations prior to the open waters. Onward from this point, the warm surface temperatures destabilize the lower ABL and larger surface heat fluxes are present. This makes the 2.5-m air temperature warmer for the first $250 \mathrm{~m}$ over the open waters. Farther downstream, the enhanced entrainment of colder air from above offsets the increased surface heat fluxes, leading to smaller $T_{a}$ near the surface.

In another experiment, a logarithmic humidity profile with $\mathrm{RH}_{i}=100 \%$ at the surface, $\mathrm{RH}_{i}=70 \%$ at $z=$ $100 \mathrm{~m}$, and constant above is used for initial conditions of relative humidity. In this experiment, labeled as $\mathrm{RH}_{i}$ $=86 \%$ in Fig. 7 , stability effects are also considered. Figure 7 portrays the impact of having a dry upper ABL during a blowing-snow event over open waters. Note that in the reference case $\left(\mathrm{RH}_{i}=100 \%\right)$ the sublimation rate is zero and the solid lines are not apparent in Figs. $7 \mathrm{~b}$ and $7 \mathrm{~d}$. Before $x=1 \mathrm{~km}$, sublimation causes the air to cool down very slightly (Fig. 7c) while enhancing continuously the water vapor content of the ABL (Fig. 7d). As the column of air surpasses the open waters, $T_{a}$ and $\mathrm{RH}_{i}$ gradually increase in response to the change in surface conditions. Although the air reaches the ice saturation point at $z=2.5 \mathrm{~m}$ over the lead, the air aloft remains subsaturated and the sublimation of blowing snow persists in the $\mathrm{ABL}$, albeit at reduced rates. In this case, sublimation eliminates $4 \%$ of the blowing snow over the lead and another $89 \%$ falls into the open waters,

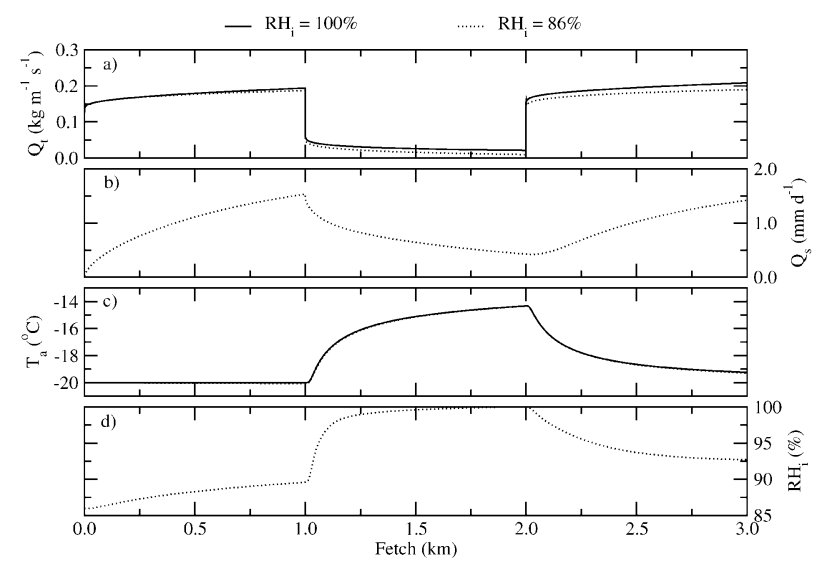

FIG. 7. The spatial evolution of the blowing snow (a) transport rate $\left(Q_{t}\right)$, (b) sublimation rate $\left(Q_{s}\right)$, (c) the air temperature $\left(T_{a}\right)$, and (d) the relative humidity with respect to ice $\left(\mathrm{RH}_{i}\right)$ as a column of blowing snow surpasses a 1-km-wide lead. Values of $T_{a}$ and $\mathrm{RH}_{i}$ are shown for $z=2.5 \mathrm{~m}$. For the simulation with $\mathrm{RH}_{i}=100 \%, Q_{s}=0$ such that solid lines are not apparent in (b) and (d).

leaving only $7 \%$ of the mass to be transported past $x=$ $2 \mathrm{~km}$. Once past the lead, vertical entrainment of relatively cold, dry air from aloft reverts the trends in the thermodynamic quantities. Unlike for $Q_{t}$, however, the memory of past surface conditions on $\mathrm{RH}_{i}$ and $T_{a}$, and hence on $Q_{s}$, persists for considerably more distance. This concurs with the results of Andreas et al. (2002) who find that the presence of a $1 \%$ lead fraction is sufficient to yield near-surface air persistently at the ice saturation point over the frozen Arctic Ocean.

\section{Sensitivity of model results to varying ambient conditions}

In this section, we investigate how variations in surface and atmospheric conditions influence $T_{\text {eff }}$ and $Q_{l}$. Figure 8 demonstrates that as the upwind fetch for blowing snow over sea ice increases, the trap efficiency and the mass lost into the leads diminish. Conversely, as the lead width expands, $T_{\text {eff }}$ and $Q_{l}$ gradually increase but begin to level off for large distances over open waters. In general, as the fetch for blowing snow over sea ice (open waters) increases, the upward transport by turbulent mixing (downward settling) of blowing snow particles increases and leads to the ever decreasing (increasing) values of $T_{\text {eff }}$ with $x$. Typical values of $T_{\text {eff }}$ range from $60 \%$ to $100 \%$ for upwind fetches spanning from 0.1 to $10 \mathrm{~km}$ over sea ice.

Figure 9 portrays the temporal evolution of $T_{\text {eff }}$ and $Q_{l}$ for a lead of $1 \mathrm{~km}$ in width and a fetch over snowcovered sea ice of $1 \mathrm{~km}$. As time marches on, $T_{\text {eff }}$ decreases rapidly in the second minute after transport initiation, reaching a steady state in about $2.5 \mathrm{~min}$. The corresponding values of $Q_{l}$ evolve to a maximum value of $18.0 \mathrm{~mm} \mathrm{day}^{-1}$ swe at $t=1.1 \mathrm{~min}$ and then decrease to a steady-state value of $16.2 \mathrm{~mm}$ day $^{-1}$ swe. The time scale for the adjustment in this situation is governed by 

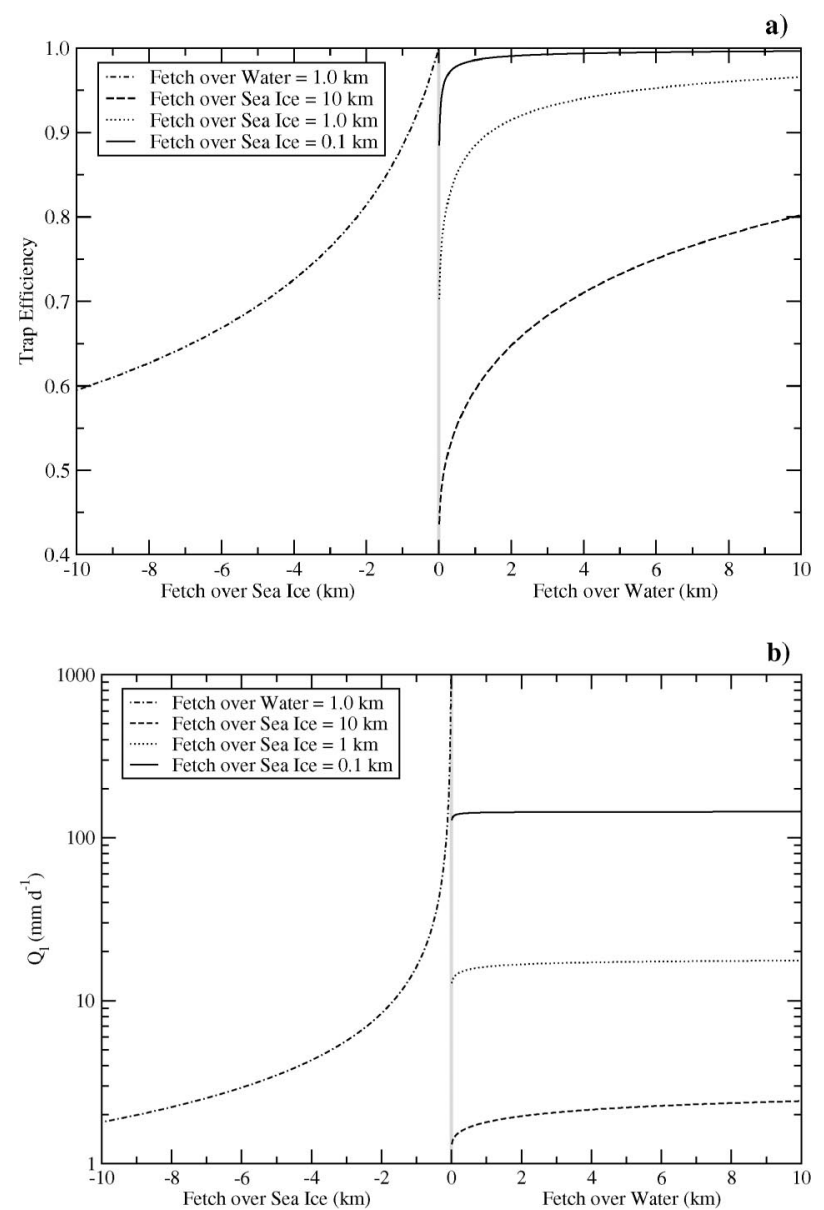

FIG. 8. (a) Values of the trap efficiency of a lead to capture blowing snow and (b) the corresponding mass lost into the lead $\left(Q_{l}, \mathrm{~mm}_{\mathrm{day}}{ }^{-1}\right.$ swe) as a function of the fetch over snow-covered sea ice and the lead width. In all cases, we assume an unlimited supply of snow on the sea ice surface available for transport.

the advective time scale $\left(=x_{f} / U_{10}=1000 \mathrm{~m} / 15 \mathrm{~m} \mathrm{~s}^{-1}\right.$ $\approx 1 \mathrm{~min}$ ) as opposed to steady-state condition over sea ice that is governed by the diffusive (vertical) time scale $(\approx 1$ day $)$.

The trap efficiency and the mass deposited into leads are also influenced by meteorological conditions. These include variations in $U_{10}, \mathrm{RH}_{i}, u_{*}$, and $T_{a}$. Each of these variables is modified within a range of values anticipated for an environment that is conducive to blowing snow events. Note that changes in $u_{*}$ from 0 to $1 \mathrm{~m} \mathrm{~s}^{-1}$ correspond to variations between 0 and 0.0044 in the drag coefficient. In Fig. 10, only one parameter is varied from the reference case at a time. Results illustrate that values of $T_{\text {eff }}$ and $Q_{l}$ are most sensitive to changes in $U_{10}$ and $u_{*}$. As wind speeds intensify, the amount of suspended particles rises rapidly as they gradually reach higher elevations. As a result, a smaller percentage of the suspended blowing snow particles settle back to the surface over the lead area. With the stronger winds, however, the transport rate of blowing snow $\left(Q_{t}\right)$ in-

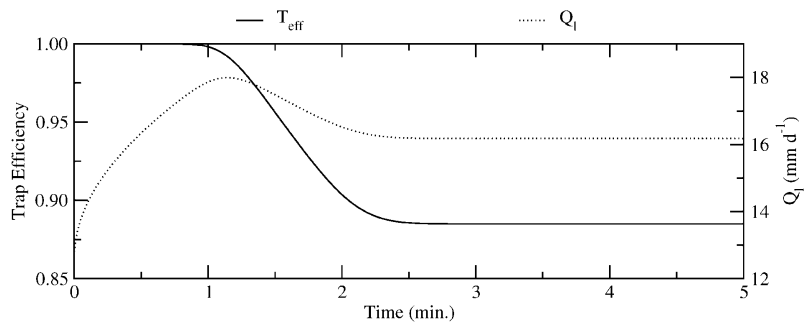

FIG. 9. Values of the trap efficiency of a lead to capture blowing snow and the corresponding mass lost into the lead $\left(Q_{l}, \mathrm{~mm}\right.$ day $^{-1}$ swe) as a function of time. An upwind fetch of $1 \mathrm{~km}$ over sea ice and a $1-\mathrm{km}$-wide lead is assumed, with $U_{10}=15 \mathrm{~m} \mathrm{~s}^{-1}$.

creases, and the snow mass lost into leads continues to increase despite the lesser values of the trap efficiencies. At these high wind speeds, additional blowing snow particles are relatively large in comparison with the overall particle spectrum, leaving these heavy particles to fall rapidly out of the atmosphere and into the open waters. Although elevated values of $u_{*}$ correspond to enhanced vertical transfer coefficients, there is a corresponding decrease in wind speed through the enhanced surface roughness and a reduction in the saltation transport rate (see section 2); the overall effect of enhancing $u_{*}$ is to decrease both $T_{\text {eff }}$ and $Q_{l}$, in contrast to $U_{10}$. In relatively dry air, sublimation of blowing snow rapidly consumes the smaller particles suspended in the ABL, thereby significantly reducing the profiles of $q_{b}$ and $N$ at high elevations above the surface. However, this does not affect much the blowing snow near the surface (where $\mathrm{RH}_{i}$ remains high and where the bulk of the mass is confined) such that variations in humidity affect marginally the total mass gained by the open waters. Note that the suspended blowing snow that sublimates does not contribute to the mass gained by the open waters. Hence, the effects of sublimation in dry conditions result in $T_{\text {eff }}$ exhibiting only a slight dependence on ambient humidity conditions. Last, $T_{\text {eff }}$ and $Q_{l}$ exhibit little variation when the ambient air temperature is varied from $-40^{\circ}$ to $0^{\circ} \mathrm{C}$. For lower values of $\mathrm{RH}_{i}$, this effect would be larger but would still remain negligible when compared with variations in $U_{10}$ and $u_{*}$.

\section{Discussion}

In the previous section, it has been demonstrated that the transport of blowing snow into open waters depends mainly on $u_{*}$ and $U_{10}$. In turn, this implies that the contribution of wind redistribution on the snow mass balance of polar sea ice will vary temporally and spatially. In marginal ice zones, for instance, where precipitation is abundant, winds are strong and open waters amply present, large values of $Q_{l}$ are to be expected. By contrast, other regions such as the central Arctic Ocean have wintertime climates dominated by persistent anticyclones and have a relatively low percentage of 

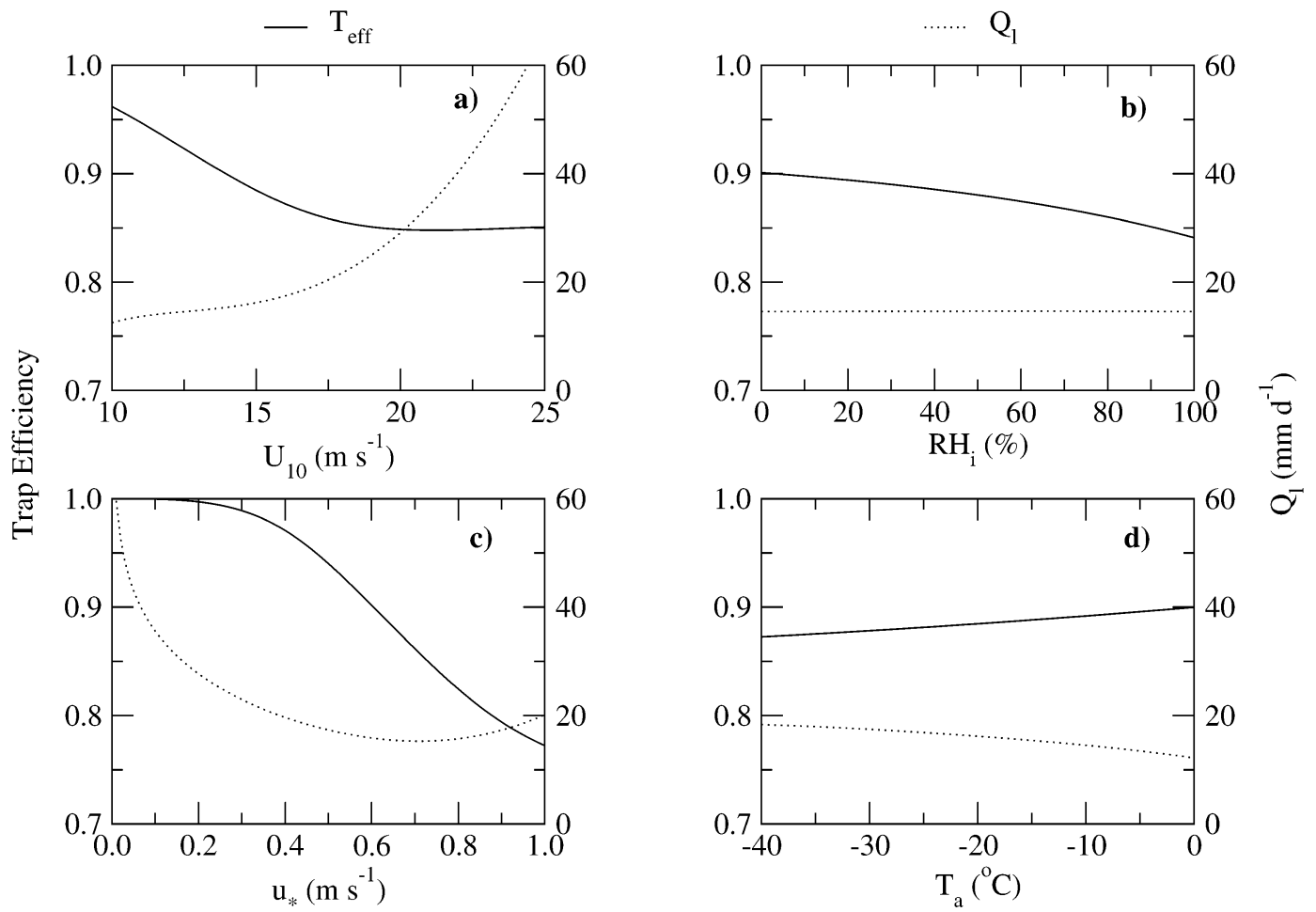

FIG. 10. Values of the trap efficiency of open waters to capture blowing snow and the corresponding mass lost into the lead $\left(Q_{l}, \mathrm{~mm}\right.$ day $\left.^{-1} \mathrm{swe}\right)$ as a function of (a) the 10 -m wind speed $\left(U_{10}\right)$, (b) the relative humidity with respect to ice $\left(\mathrm{RH}_{i}\right)$, (c) the friction velocity $\left(u_{*}\right)$, and (d) the air temperature $\left(T_{a}\right)$. An upwind fetch of $1 \mathrm{~km}$ over sea ice is assumed, and steady-state results are presented.

open waters; this will reduce the importance of blowing snow in the local snow mass balance.

To illustrate some of the effects of regional variations in ambient conditions on the loss of airborne snow into leads, Fig. 11 presents values of $Q_{l}$ as a function of $Q_{t}^{\text {in }}$ and $T_{\text {eff }}$. In this analysis, $x_{f}=10 \mathrm{~km}$ based on a mean lead width of $100 \mathrm{~m}$ [a typical value in the Arctic Ocean; Wadhams (2000)] and a 1\% coverage of open

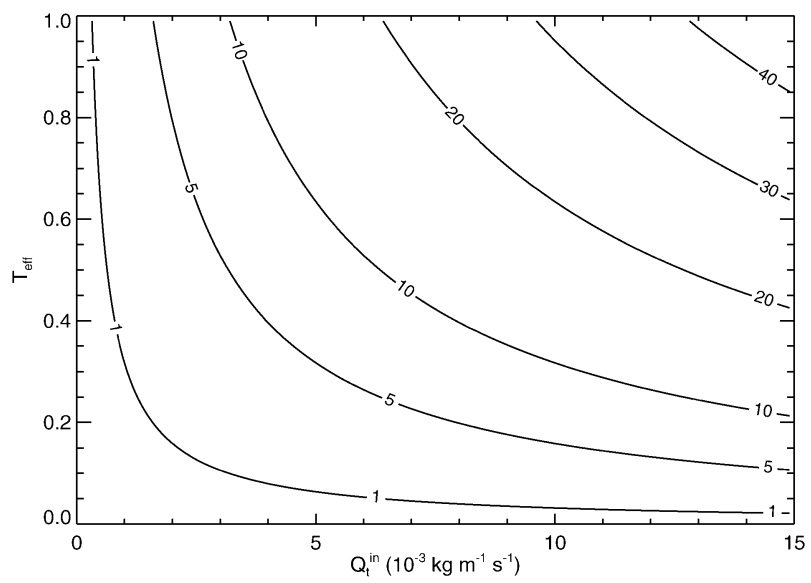

FIG. 11. Contours of the snow mass $\left(Q_{l}, \mathrm{~mm} \mathrm{yr}^{-1}\right.$ swe $)$ lost into open waters as a function of the transport rate of blowing snow $\left(Q_{t}^{\text {in }}\right)$ and the trap efficiency $\left(T_{\text {eff }}\right)$. waters (Andreas et al. 2002). Note that the range of $Q_{t}^{\text {in }}$ values provided here is typical for yearly mass fluxes of blowing snow over the Arctic Ocean (DY02). Figure 11 shows that, as transport rates of blowing snow and trap efficiencies of leads are enhanced, the snow mass eroded over sea ice increases. For a typical $T_{\text {eff }}=80 \%$ and $Q_{t}^{\text {in }}=8 \times 10^{-3} \mathrm{~kg} \mathrm{~m}^{-1} \mathrm{~s}^{-1}, Q_{l}=20 \mathrm{~mm} \mathrm{yr}^{-1}$ swe. This indicates that wind redistribution of snow into open waters can be a significant sink term in the surface mass balance in regions where $T_{\text {eff }}$ and $Q_{t}$ are large, and if the distance between individual leads remains small.

Another question that arises from the above discussion is whether a large number of relatively small leads are more efficient at extracting snow mass from the surface of the Arctic sea ice cover than a few large leads. In this final experiment, we vary the total number of leads while keeping the total open area constant. In all experiments, we maintain a $1 \%$ fraction of open waters over a 3000-km domain. Figure 12 illustrates that a linear relationship exists between the mass lost into open waters and the number of leads in the sea ice cover. This hints at the fact that the snow mass loss into leads could be simply parameterized as a function of the lead distribution for a given wind speed, air temperature, and humidity. Future work will involve similar simulations over larger spatial domains, and using more realistic lead distributions (e.g., Lindsey and Rothrock 1995; Wadhams 2000; Kwok 2002). 


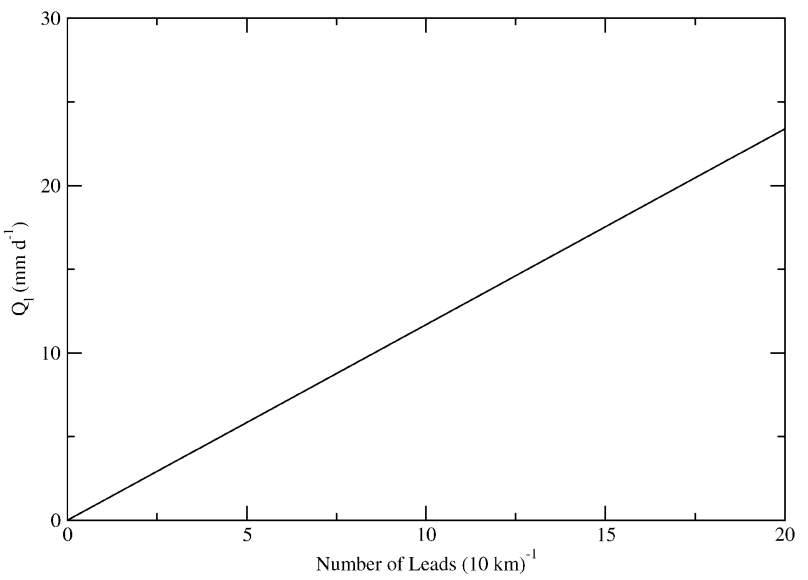

FIG. 12. The snow mass $\left(Q_{l}, \mathrm{~mm} \mathrm{day}^{-1}\right.$ swe) lost into open waters as a function of the number of leads. In all experiments, the total lead fraction remained constant at $1 \%$ over the entire domain.

Prior versions of the PIEKTUK model have been extensively tested against measurements of blowing snow particles collected in Wyoming and Antarctica (Xiao 2001). To validate the new features incorporated into PIEKTUK-TUVAQ, precise field measurements of meteorological, snow, and sea ice conditions of an Arctic site will be required. Meteorological conditions such as wind, air temperature, and humidity remain the critical input parameters for this model. Of particular importance is the spatial and temporal characterization of the snowpack, including its thickness, density, and heat content (Lynch-Stieglitz 1994). Furthermore, information on surface roughness length, friction velocity, and threshold at which blowing snow is initiated will be helpful to calibrate various model parameterizations. To this end, several mass balance sites (chosen at regular intervals) along a planned snow course would provide data on the surface topography and the snowpack evolution over a given area. Measurements made at different heights during the full cycle of a storm would provide useful information to validate the evolution of $N$ profiles for various atmospheric conditions. Although the acquisition of measurements in harsh environments such as the Arctic remains particularly difficult, there are plans to collect such comprehensive records of snow distribution and redistribution events as part of the Canadian Arctic Shelf Exchange Study (CASES; J. M. Hanesiak 2003, personal communication). This will provide the required data for a more rigorous test of PIEKTUK-TUVAQ under realistic (rather than idealized) conditions.

Indirect evidence also hints at the fact that blowing snow may be important for the full closure of the Arctic snow mass budget. The dominant source and sink terms in the snow mass budget have generally been associated with precipitation, melt, and surface sublimation; however, recent studies have not been able to close the snow mass budget within reasonable error considering the three main terms alone (T. E. Arbetter and J. A. Curry 2003, personal communication). This suggests that other processes may also come into play. Of these processes, snow mass lost associated with blowing snow effects may be more important than first anticipated and could account for the discrepancies. In fact, a preliminary analysis using PIEKTUK-TUVAQ to the Arctic domain seems to provide near closure of the snow mass budget (work in progress).

\section{Summary and future applications}

A model of blowing snow over sea ice is presented. The PIEKTUK-D model has been modified to take into account heterogeneous surfaces such as leads and snowdrifts, and the effects of atmospheric stability on the blowing snow process. The new model (entitled PIEKTUK-TUVAQ) was applied in idealized settings to investigate the impact of two surface features on the transport rates of blowing snow. In the first situation, we investigated the trap efficiency of open waters to capture blowing snow. The simulations demonstrated that, under a wide range of ambient conditions, leads typically collect between $60 \%$ and $100 \%$ of the mass transported within a column of blowing snow. Several factors were shown to significantly influence the trap efficiency of the open waters to capture blowing snow, including the fetch for blowing snow over sea ice and open waters, as well as the ambient conditions of wind speed and friction velocity. In contrast, the relative humidity and the air temperature were shown to have a smaller influence. In a second experiment, the model depicted the evolution of a snowdrift as it formed a barrier to the low-level flow. It was shown that the snowdrift expands in time while creating a zone of mass erosion farther downwind. The heterogeneity in snow thickness from interactions between winds and the surface, however, is shown to have a minimal impact on the conductive heat flux through the ice for a typical snowdrift distribution. Additional simulations demonstrated that the effects of stability and sublimation on the mass transport rates were minimal but led to notable changes in the ambient thermodynamic conditions.

This study suggests that blowing snow can alter significantly surface conditions of snow-covered sea ice. Some preliminary results demonstrate that a simple linear function exists between the mass lost into open waters and the number of leads in the sea ice cover. To generalize this relationship, future work will focus on the derivation of a parameterization of snow mass lost into leads based on ambient meteorological conditions and surface lead characteristics. To this end, PIEKTUKTUVAQ will be run on a realistic domain (horizontal dimensions of about $3000 \mathrm{~km}$ ) using a range of wind speeds, surface roughness, and lead distributions in accord with those derived from satellite (Lindsey and Rothrock 1995) or submarine (Wadhams 2000) measurements. This parameterization will then be used in a 
high-resolution $(1 \mathrm{~km}) 3 \mathrm{D}$ regional atmospheric model and the results will be compared with simulations from the same model but with a surface lead distribution specified from the Radarsat Geophysical Processor System (RGPS) data at the Jet Propulsion Laboratory (Kwok 2002). This will build on the previous work by Déry and Yau (2001a) who made similar simulations using a coupled blowing snow/atmosphere model but without considering leads at the surface. In parallel, we intend to couple PIEKTUK-TUVAQ to the sea ice model of Tremblay and Mysak (1997) to evaluate the precise role that blowing snow plays in the surface mass balance of polar sea ice and on the conductive heat flux through sea ice using specified atmospheric forcing.

Acknowledgments. We thank Dr. Judith A. Curry (Georgia Institute of Technology) and Dr. Todd E. Arbetter (Cooperative Institute for Research in Environmental Sciences) for providing the initial impetus for this study, Dr. John M. Hanesiak (University of Manitoba) for insightful discussions on blowing snow over sea ice, Dr. Ian J. Walker (University of Victoria) for insights on airflow near sand and snow dunes, and $\mathrm{Mr}$. Jason Hyatt (Massachusetts Institute of Technology and Woods Hole Oceanographic Institute) for useful remarks on our work. Dr. Dave G. Barber (University of Manitoba) and one anonymous referee provided valuable comments on the manuscript. Author S. J. Déry was supported by National Science Foundation Grant OPP0002369 and by National Aeronautics and Space Agency Grant NAG5-9759, and B. Tremblay was supported by National Science Foundation Grants OPP98-18711 and OPP-0230264.

\section{REFERENCES}

Anderson, R. S., and P. K. Haff, 1991: Wind modification and bed response during saltation of sand in air. Acta Mech., 1 (Suppl.), 21-52.

Andreas, E. L, 1995: Air-ice drag coefficients in the western Weddell Sea, 2. A model based on form drag and drifting snow. J. Geophys. Res., 100, 4833-4843.

, and K. J. Claffey, 1995: Air-ice drag coefficients in the western Weddell Sea, 1. Values deduced from profile measurements. $J$. Geophys. Res., 100, 4821-4831.

_ , P. S. Guest, P. O. G. Persson, C. W. Fairall, T. W. Horst, R. E. Moritz, and S. R. Semmer, 2002: Near-surface water vapor over polar sea ice is always near ice-saturation. J. Geophys. Res., 107 (C8), 8033, doi:10.1029/2000JC000411.

Arya, S. P., 2001: Introduction to Micrometeorology. $2 \mathrm{~d}$ ed. Academic Press, 420 pp.

Bintanja, R., 2000a: Snowdrift suspension and atmospheric turbulence. Part I: Theoretical background and model description. Bound.-Layer Meteor., 95, 343-368.

, 2000b: Snowdrift suspension and atmospheric turbulence. Part II: Results of model simulations. Bound.-Layer Meteor., 95, 369-395.

_ 2001: Modification of the wind speed profile caused by snowdrift: Results from observations. Quart. J. Roy. Meteor. Soc., 127, 2417-2434.

Budd, W. F., 1966: The drifting of non-uniform snow particles. Studies in Antarctic Meteorology, M. J. Rubin, Ed., Antarctic Research Series, Vol. 9, Amer. Geophys. Union, 59-70.
Cavalieri, D. J., P. Gloersen, C. L. Parkinson, J. C. Comiso, and H. J. Zwally, 1997: Observed hemispheric asymmetry in global sea ice changes. Science, 278, 1104-1106.

Charnock, H., 1958: A note on empirical wind-wave formulae. Quart. J. Roy. Meteor. Soc., 84, 443-447.

Colony, R., V. Radionov, and F. J. Tanis, 1998: Measurements of precipitation and snow pack at Russian North Pole drifting stations. Polar Rec., 34, 3-14.

Déry, S. J., and P. A. Taylor, 1996: Some aspects of the interaction of blowing snow with the atmospheric boundary layer. Hydrol. Processes, 10, 1345-1358.

— weather events. J. Geophys. Res., 104 (D14), 16 657-16 672.

— Meteor., 93, 237-251.

— a coupled blowing snow-atmosphere model. J. Hydrometeor., 2, 479-498.

— , and _ 2001b: Simulation of blowing snow in the Canadian Arctic using a double-moment model. Bound.-Layer Meteor., 99, 297-316.

_ , and —_, 2002: Large-scale mass balance effects of blowing snow and surface sublimation. J. Geophys. Res., 107, 4679, doi: 10.1029/2001JD001251.

_ _ P. A. Taylor, and J. Xiao, 1998: The thermodynamic effects of sublimating, blowing snow in the atmospheric boundary layer. Bound.-Layer Meteor., 89, 251-283.

Doorschot, J. J. J., and M. Lehning, 2002: Equilibrium saltation: Mass fluxes, aerodynamic entrainment, and dependence on grain properties. Bound.-Layer Meteor., 104, 111-130.

Eicken, H., M. A. Lange, H.-W. Hubberten, and P. Wadhams, 1994: Characteristics and distribution patterns of snow and meteoric ice in the Weddell Sea and their contribution to the mass balance of sea ice. Ann. Geophys., 12, 80-93.

Fichefet, T., and M. A. Morales Maqueda, 1999: Modelling the influence of snow accumulation and snow-ice formation on the seasonal cycle of the Antarctic sea-ice cover. Climate Dyn., 15, $251-268$.

Gibson, J. K., P. Kållberg, S. Uppala, A. Hernandez, and E. Serrano, 1997: ERA description. ECMWF Re-Analysis Project Report Series, Vol. 1, European Centre for Medium-Range Weather Forecasts, $72 \mathrm{pp}$.

Hanesiak, J. M., D. G. Barber, and G. M. Flato, 1999: Role of diurnal processes in the seasonal evolution of sea ice and its snowcover. J. Geophys. Res., 104 (C6), 13 593-13 603.

Hunt, B. G., H. B. Gordon, and H. L. Davies, 1995: The impact of the greenhouse effect on sea-ice characteristics and snow accumulation in the polar regions. Int. J. Climatol., 15, 3-23.

Iacozza, J., and D. G. Barber, 1999: An examination of the distribution of snow on sea-ice. Atmos.-Ocean, 37, 21-51.

Jordan, R. E., E. L Andreas, and A. P. Makshtas, 1999: Heat budget of snow-covered sea ice at North Pole 4. J. Geophys. Res., 104 (C4), 7785-7806.

, - C. W. Fairall, A. A. Grachev, P. S. Guest, J. M. Hanesiak, D. K. Perovich, and P. O. G. Persson, 2003: Modeling surface exchange and heat transfer for the shallow snow cover at SHEBA. Preprints, Seventh Conf. on Polar Meteorology and Oceanography, Hyannis, MA, Amer. Meteor. Soc., CD-ROM, 3.3.

King, J. C., and J. Turner, 1997: Antarctic Meteorology and Climatology. Cambridge University Press, $409 \mathrm{pp}$.

Kwok, R., 2002: Arctic sea-ice area and volume production: 1996/ 97 versus 1997/98. Ann. Glaciol., 34, 447-453.

Li, L., and J. W. Pomeroy, 1997: Estimates of threshold wind speeds for snow transport using meteorological data. J. Appl. Meteor., 36, 205-213.

Lindsey, R. W., and D. A. Rothrock, 1995: Arctic sea-ice leads from Advanced Very High Resolution Radiometer images. J. Geophys. Res., 100 (C3), 4533-4544.

Liston, G. E., and M. Sturm, 1998: A snow-transport model for complex terrain. J. Glaciol., 44, 498-516. 
Lynch-Stieglitz, M., 1994: The development and validation of a simple snow model for the GISS GCM. J. Climate, 7, 1842-1855.

Mann, G. W., 1998: Surface heat and water vapour budgets over Antarctica. Ph.D. thesis, University of Leeds, 279 pp.

- P. S. Anderson, and S. D. Mobbs, 2000: Profile measurements of blowing snow at Halley, Antarctica. J. Geophys. Res., 105 (D19), 24 291-24 308.

Massom, R. A., and Coauthors, 2001: Snow on Antarctic sea ice. Rev. Geophys., 39, 413-444.

Miller, J. R., and G. L. Russell, 2000: Projected impact of climate change on the freshwater and salt budgets of the Arctic Ocean by a global climate model. Geophys. Res. Lett., 27, 1183-1186.

Oke, T. R., 1987: Boundary Layer Climates. 2d ed. Methuen, 435 $\mathrm{pp}$

Pinto, J. O., J. A. Curry, and K. L. McInnes, 1995: Atmospheric convective plumes emanating from leads, 1. Thermodynamic structure. J. Geophys. Res., 100 (C3), 4621-4631.

Pomeroy, J. W., and D. M. Gray, 1990: Saltation of snow. Water Resour. Res., 26, 1583-1594.

_ P. Marsh, and D. M. Gray, 1997: Application of a distributed blowing snow model to the Arctic. Hydrol. Processes, 11, 14511464.

Rigor, I. G., J. W. Wallace, and R. L. Colony, 2002: Response of sea ice to the Arctic Oscillation. J. Climate, 15, 2648-2663.

Rothrock, D. A., Y. Yu, and G. A. Maykut, 1999: Thinning of the Arctic sea-ice cover. Geophys. Res. Lett., 26, 3469-3472.

Schmidt, R. A., 1982: Vertical profiles of wind speed, snow concentrations, and humidity in blowing snow. Bound.-Layer Meteor. 23, 223-246.

Semtner, A. J., 1976: A model for the thermodynamic growth of sea ice in numerical investigations of climate. J. Phys. Oceanogr., 6, 379-389.

Serreze, M. C., and Coauthors, 2000: Observational evidence of re- cent change in the northern high-latitude environment. Climatic Change, 46, 159-207.

Stull, R. B., 1988: An Introduction to Boundary Layer Meteorology. Kluwer Academic, 666 pp.

Sturm, M., J. Holmgren, and D. K. Perovich, 2002: Winter snow cover on the sea ice of the Arctic Ocean at the Surface Heat Budget of the Arctic Ocean (SHEBA): Temporal evolution and spatial variability. J. Geophys. Res., 107, 8047, doi:10.1029/ 2000JC000400.

Taylor, P. A., 1969: On planetary boundary layer flow under conditions of neutral thermal stability. J. Atmos. Sci., 26, 427-431.

Tremblay, L.-B., and L. A. Mysak, 1997: Modeling sea ice as a granular material, including the dilatancy effect. J. Phys. Oceanogr., 27, 2342-2360.

Vinnikov, K. Y., and Coauthors, 1999: Global warming and Northern Hemisphere sea ice extent. Science, 286, 1934-1937.

Wadhams, P., 2000: Ice in the Ocean. Gordon and Breach, $351 \mathrm{pp}$.

Walker, I. J., and W. G. Nickling, 2002: Dynamics of secondary airflow and sediment transport over and in the lee of transverse dunes. Prog. Phys. Geogr., 26, 47-75.

Walsh, J. E., 2000: Global atmospheric circulation patterns and relationships to Arctic freshwater fluxes. The Freshwater Budget of the Arctic Ocean, E. L. Lewis, Ed., Kluwer Academic, 2143.

Warren, S. G., I. G. Rigor, N. Untersteiner, V. F. Radionov, N. N. Bryazgin, Y. I. Aleksandrov, and R. Colony, 1999: Snow depth on Arctic sea ice. J. Climate, 12, 1814-1829.

Xiao, J., 2001: A model of the transport and sublimation of blowing snow in the atmospheric boundary layer. Ph.D. thesis, York University, $227 \mathrm{pp}$.

— , R. Bintanja, S. J. Déry, G. W. Mann, and P. A. Taylor, 2000: An intercomparison among four models of blowing snow. Bound.-Layer Meteor., 97, 109-135. 